\title{
Barodesy for clay
}

\author{
G. MEDICUS*, W. FELLIN* and D. KOLYMBAS*
}

\begin{abstract}
Barodesy is a new hypoplastic frame for constitutive models to describe granular materials. It has already been introduced for sand, and this article adjusts barodesy for clay. Common concepts of soil mechanics, such as critical states, barotropy (i.e. the dependence of stiffness and strength on the stress level), pyknotropy (i.e. the dependence of stiffness and strength on density) and a stressdilatancy relation can easily be included in the presented model. Despite its mathematical simplicity, barodesy is able to describe many aspects of clay behaviour. Only four material constants are required, which can be determined by means of a single consolidated undrained triaxial test.
\end{abstract}

KEYWORDS: clays; constitutive relations

ICE Publishing: all rights reserved

\section{INTRODUCTION}

A new constitutive frame for soil called 'barodesy', proposed by Kolymbas $(2009,2011,2012)$ and conceived as an evolution equation of the type $\mathbf{T}=\mathbf{T}(\mathbf{T}, \mathbf{D}, e)$, is based on the asymptotic behaviour of granulates. It can also be considered as a further development of hypoplasticity (Kolymbas, 1977, 1985, 1991, 2000). Barodesy is derived from two rules proposed by Goldscheider (1976), based on the results of true triaxial tests. He applied proportional strain paths to sand samples and observed the corresponding stress paths. Proportional strain paths are paths with constant ratios of the principal strains (i.e. $\varepsilon_{1}: \varepsilon_{2}: \varepsilon_{3}=$ constant. In the same sense, paths with constant ratios of the principal stresses are called proportional stress paths (i.e. $\sigma_{1}: \sigma_{2}: \sigma_{3}=$ constant). Goldscheider (1976) formulated the following two rules.

- Rule 1. Starting at a stress-free state $\mathbf{T}=\mathbf{0}$, proportional strain paths lead to proportional stress paths (see Fig. 1(a) and Fig. 1(b)).

- Rule 2. Starting at $\mathbf{T} \neq \mathbf{0}$, proportional strain paths lead asymptotically to the corresponding proportional stress paths starting at $\mathbf{T}=\mathbf{0}$ (see Fig. 1(a) and Fig. 1(c)). This means that proportional stress paths act as attractors.

\section{SYMBOLS AND NOTATION}

We adhere to the symbolic notation of stress with $\mathbf{T}$ but, in some cases, we use for the principal stresses the more familiar symbol $\sigma_{i}$ instead of $T_{i}$. The stretching tensor $\mathbf{D}$ (i.e. the symmetric part of the velocity gradient) corresponds approximately to the strain rate, but is strictly speaking not the time rate of any strain measure. Superscript 0 denotes a normalised tensor (i.e. $\mathbf{X}^{0}=\mathbf{X} /|\mathbf{X}|$ with $|\mathbf{X}|=\left(\operatorname{tr} \mathbf{X}^{2}\right)^{1 / 2}$. The following abbreviations are used: $\epsilon:=\operatorname{tr} \mathbf{D}^{0}, \sigma:=|\mathbf{T}|, \dot{\varepsilon}:=|\mathbf{D}|$. Stresses should be understood as effective ones; the normally used dash is omitted here for brevity, even for $p:=-(1 / 3)$ $\operatorname{tr} \mathbf{T}$. As in this article only rectilinear extensions are examined, the co-rotational stress rate $\mathbf{\mathbf { T }}$ is replaced with $\mathbf{T}$. The void ratio $e$ is, as usual, the ratio of the volume of the voids $V_{\mathrm{p}}$ to the

Manuscript received 5 June 2012; first decision 25 July 2012; accepted 15 August 2012.

Published online at www.geotechniqueletters.com on 23 October 2012.

*Division of Geotechnical and Tunnel Engineering, University of Innsbruck, Innsbruck, Austria volume of the solids $V_{\mathrm{s}}$. $p$ is the mean effective stress and $\varepsilon_{\mathrm{v}}=$ $\operatorname{tr} \varepsilon$ is the volumetric strain. For a conventional triaxial compression test, the axial stress is denoted with $\sigma_{1}$ and the radial stress is denoted with $\sigma_{2}\left(=\sigma_{3}\right)$. The associated strains are $\varepsilon_{1}$ and $\varepsilon_{2}=\varepsilon_{3}$. Recall that in critical state soil mechanics (CS $\mathrm{SM})$, the variables $q:=\sigma_{1}-\sigma_{3}$ and $\varepsilon_{\mathrm{q}}:=2 / 3 \cdot\left(\varepsilon_{1}-\varepsilon_{3}\right)$ are used.

\section{CONSTITUTIVE EQUATION}

The directions $\mathbf{R}$ of proportional stress paths starting at $\mathbf{T}=\mathbf{0}$ and obtained with proportional strain paths $\mathbf{D}=$ constant are given by (Kolymbas, 2009)

$$
\mathbf{R}(\mathbf{D})=\left(\operatorname{tr} \mathbf{D}^{0}\right) \mathbf{1}+c_{1} \exp \left(c_{2} \mathbf{D}^{0}\right)
$$

where $c_{1}$ and $c_{2}$ are constants. ${ }^{1}$

The general form of the barodetic constitutive relation is (Kolymbas, 2011)

$$
\dot{\mathbf{T}}=h(\sigma) \cdot\left(f \mathbf{R}^{0}+g \mathbf{T}^{0}\right) \dot{\varepsilon}
$$

with $h=c_{3} \sigma^{c_{4}}$, where $c_{3}$ and $c_{4}$ are material constants.

In this article, a new formulation of the functions $f$ and $g$ (e.g. for sand, it can be set $f=\mathrm{c}_{5} \epsilon-e_{\mathrm{c}}$ and $g=e$ ) to model clay behaviour is used

$$
f=c_{5} \epsilon-\ln \left(1+e_{\mathrm{c}}\right)
$$

$$
g=\ln (1+e)
$$

The scalar functions $f$ and $g$ take into account critical states, barotropy and pyknotropy. How $f$ and $g$ are derived, based on concepts of CSSM, is shown in the following section. The quantity $e_{\mathrm{c}}$ is the stress-dependent critical void ratio (see equation (6) and $c_{5}$ is a material constant. Equations (1)-(4) are the full set of barodetic equations for clay. Note that the notation of the material constants $c_{1}-c_{5}$ is chosen according to Kolymbas (2011).

${ }^{1}$ Note that the exponential of a tensor $\mathbf{A}$ can be defined by means of its eigenvalues $a_{i}$

$$
\exp \mathbf{A}=\exp \left(\begin{array}{ccc}
a_{1} & 0 & 0 \\
0 & a_{2} & 0 \\
0 & 0 & a_{3}
\end{array}\right)=\left(\begin{array}{ccc}
\exp a_{1} & 0 & 0 \\
0 & \exp a_{2} & 0 \\
0 & 0 & \exp a_{3}
\end{array}\right)
$$




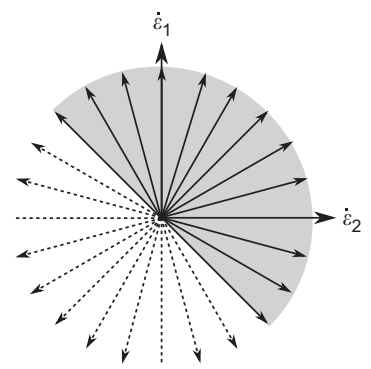

(a)

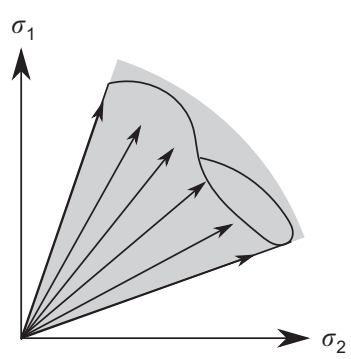

(b)

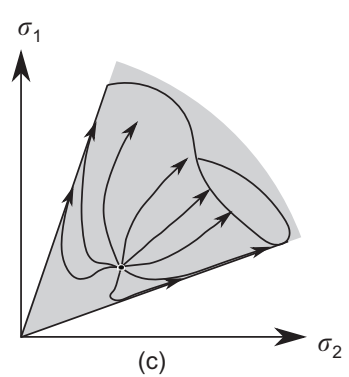

Fig. 1. (a) Proportional strain paths. (b) Proportional stress paths. (c) Asymptotic behaviour

\section{LINKS TO CRITICAL STATE SOIL MECHANICS}

We start from two well-known equations from CSSM.

- The isotropic normal consolidation line (NCL) (Butterfield, 1979)

$\ln (1+e)=N-\lambda \ln \frac{p}{p_{\mathrm{r}}}$

in which $N$ is the ordinate intercept (i.e. $N=\ln (1+e)$ at $p$ $=p_{\mathrm{r}}=1 \mathrm{kPa}$ and $\lambda$ is the slope of the NCL (see Fig. 2(a)). (Note that, usually, the quantities $N$ and $\lambda$ are defined in a $\ln p-(1+e)$ plot, whereas the symbols $N^{*}$ and $\lambda^{*}$ are used with reference to $\ln p-\ln (1+e)$ plots. In this article, we write $N$ and $\lambda$ for brevity instead of $N^{*}$ and $\lambda^{*}$.)

- The critical state line (CSL) is defined as follows and is parallel to the NCL

$\ln \left(1+e_{\mathrm{c}}\right)=N-\lambda \ln \frac{2 p}{p_{\mathrm{r}}}$

Note that according to the so-called 'state boundary surface' of the modified Cam clay model (MCCM) (Roscoe \& Burland, 1968) the ordinate intercepts of the CSL and NCL are related (see Fig. 2(a)).

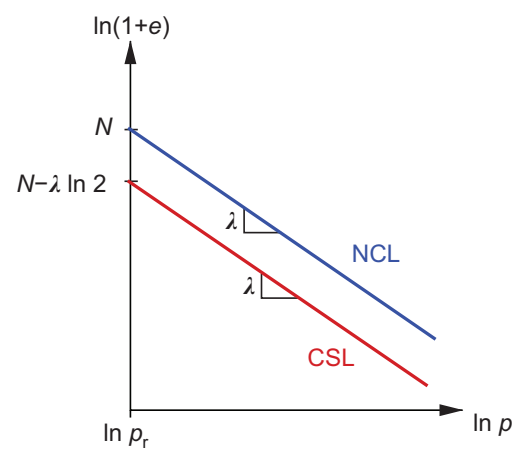

(a)
Critical states are characterised by a vanishing stress rate $\dot{\mathbf{T}}=\mathbf{0}$ and isochoric deformation $\epsilon=0$. According to equation (2), the condition $\dot{\mathbf{T}}=\mathbf{0}$ implies that $\mathbf{R}^{0}=\mathbf{T}^{0}$ and $f+g=0$. From equations (2) and (6), we get, for critical states $\left(e=e_{\mathrm{c}}\right.$ and $\left.\epsilon=0\right)$

$$
f+g=0=\ln \left(1+e_{\mathrm{c}}\right)-N+\lambda \ln \frac{2 p}{p_{\mathrm{r}}}
$$

The following generalisation for non-isochoric deformations $\left(e \neq e_{\mathrm{c}}, \epsilon \neq 0\right)$ is assumed

$$
f+g=\ln (1+e)-N+\lambda \ln \frac{2 p}{p_{\mathrm{r}}}+c_{5} \epsilon
$$

With equation (6), it follows that

$$
f+g=\ln (1+e)-\ln \left(1+e_{\mathrm{c}}\right)+c_{5} \epsilon
$$

The following partition of $f+g$ is chosen:

$$
\begin{aligned}
& f=c_{5} \epsilon-\ln \left(1+e_{\mathrm{c}}\right) \\
& g=\ln (1+e)
\end{aligned}
$$

It should be mentioned that the critical state surface (Fig. 3(b)) depends only on the critical friction angle $\varphi_{\mathrm{c}}$ and practically coincides with the Matsuoka-Nakai failure criterion (Fellin \& Ostermann, 2011) (Fig. 3(a)).

\section{CALIBRATION}

Experimental results with Dresden clay were used for the calibration (Dresden clay data are taken from Bergholz (2009)). For determination of the four parameters of CSSM $\left(N, \lambda, \varphi_{\mathrm{c}}\right.$ and $\left.\hat{G}_{0}\right)$, an isotropic compression test and an undrained triaxial test are sufficient. Both are performed in the course of a consolidated undrained (CU) triaxial test.

The slope $\lambda$ and the intercept $N$ of the NCL are obtained from the isotropic compression (Fig. 2). The critical friction angle $\varphi_{\mathrm{c}}$ can be determined, for example, by an undrained triaxial compression test (Fig. 4). The slope of the CSL in the $p-q$ plane is

$$
\frac{q_{\mathrm{c}}}{p_{\mathrm{c}}}=\frac{6 \sin \varphi_{\mathrm{c}}}{3-\sin \varphi_{\mathrm{c}}}
$$

From a critical stress state, $\varphi_{\mathrm{c}}$ can be obtained

$$
\sin \varphi_{\mathrm{c}}=\frac{3 q_{\mathrm{c}}}{q_{\mathrm{c}}+6 p_{\mathrm{c}}}
$$

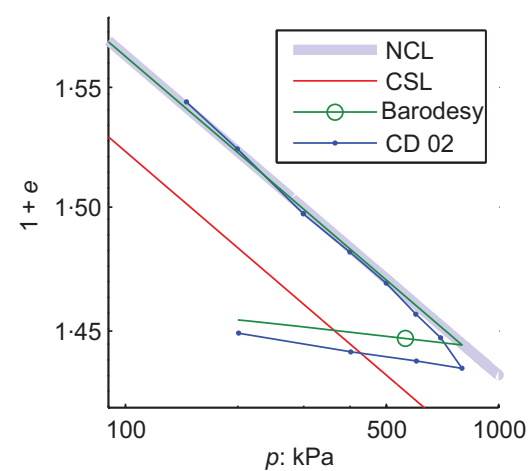

(b)

Fig. 2. Normal compression line (NCL) and critical state line (CSL). (a) Schematic diagram. (b) Isotropic compression: experimental results with Dresden clay CD 02 and numerical simulation with barodesy, $\ln (1+e)$ versus $\ln p$ plot 


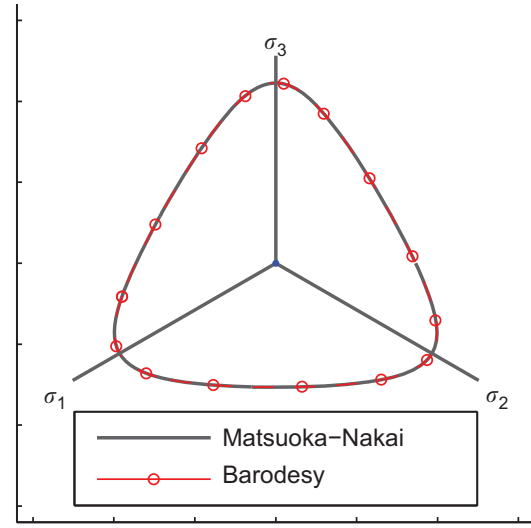

(a)

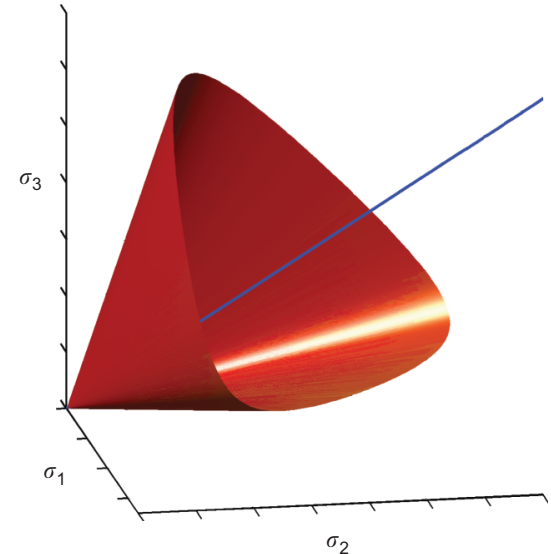

(b)

Fig. 3. Critical state surface obtained with equation (1). (a) Matsuoka-Nakai failure surface and critical state surface obtained with barodesy. (b) Critical state surface according to barodesy

Now we consider the initial stiffness of an undrained triaxial compression test. It is common to express the stiffness $\partial q / \partial \varepsilon_{q}$ by means of the shear modulus $G$

$$
G=\frac{1}{3} \frac{\partial q}{\partial \varepsilon_{q}}
$$

The initial value for $G$ is $G_{0}=\left.G\right|_{\varepsilon_{q}=0}$ (see Fig. 5(a)). Normalising the stiffness $G$ with the consolidation pressure $p_{0}$ (see Fig. 4(a)) and with the critical void ratio at this pressure $e_{\mathrm{c}}\left(p_{0}\right)$ yields

$$
\hat{G}:=\frac{G}{p_{0} \cdot e_{\mathrm{c}}\left(p_{0}\right)}
$$

It can be seen in Fig. 5(b), that the dependence of $\hat{G}$ on $\varepsilon_{q}$ unifies undrained triaxial test results obtained with various $p_{0}$ values. The influence of $\hat{G}_{0}:=\left.\hat{G}\right|_{\varepsilon_{q}=0}$ on the simulations of drained triaxial tests with barodesy is rather small (see Fig. 6).

The method of calibrating the constants $c_{1}-c_{5}$ on the basis of the aforementioned parameters $\varphi_{\mathrm{c}}, N, \lambda$ and $\hat{G}_{0}$ is now described.

\section{Calibration of $\mathrm{c}_{2}$}

At critical states, the stress rate vanishes, $\mathbf{T}=\mathbf{0}$. Consequently, $\mathbf{R}$ is proportional to $\mathbf{T}$, i.e. $\mathbf{R}^{0}=\mathbf{T}^{0}$ (see equation (2)). For an undrained triaxial test, the dilatancy vanishes, i.e. $\epsilon=0$ and

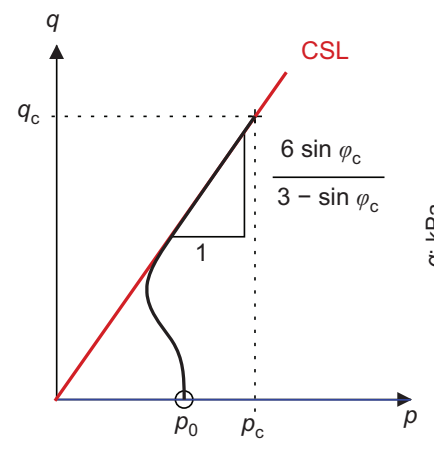

(a)

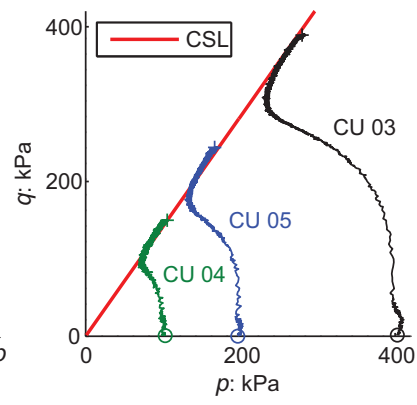

(b)
Fig. 4. Calibration of $\varphi_{c}$ on the basis of $\mathrm{CU}$ tests. The experimental results in (b) (CU 03, CU 04 and CU 05) were obtained with Dresden clay the asymptotic stress ratio is given by the critical friction angle $\varphi_{\mathrm{c}}$ (Fig. 4). With

$$
K_{\mathrm{c}}:=\frac{1-\sin \varphi_{\mathrm{c}}}{1+\sin \varphi_{\mathrm{c}}}=\frac{\sigma_{2}}{\sigma_{1}}=\frac{R_{2}}{R_{1}}=\exp \left(c_{2} D_{2}^{0}-c_{2} D_{1}^{0}\right)
$$

it follows that

$$
c_{2}=\frac{\ln K_{\mathrm{c}}}{D_{2}^{0}-D_{1}^{0}}=\left(\frac{2}{3}\right)^{1 / 2} \ln K_{\mathrm{c}}=\left(\frac{2}{3}\right)^{1 / 2} \ln \frac{1-\sin \varphi_{\mathrm{c}}}{1+\sin \varphi_{\mathrm{c}}}
$$

\section{Calibration of $c_{1}$}

We consider the peak of a drained triaxial (CD) test with $\dot{\mathbf{T}}=\mathbf{0}$ and

$$
K_{\mathrm{a}}:=\frac{\sigma_{2}}{\sigma_{1}}=\frac{1-\sin \varphi_{\mathrm{p}}}{1+\sin \varphi_{\mathrm{p}}} .
$$
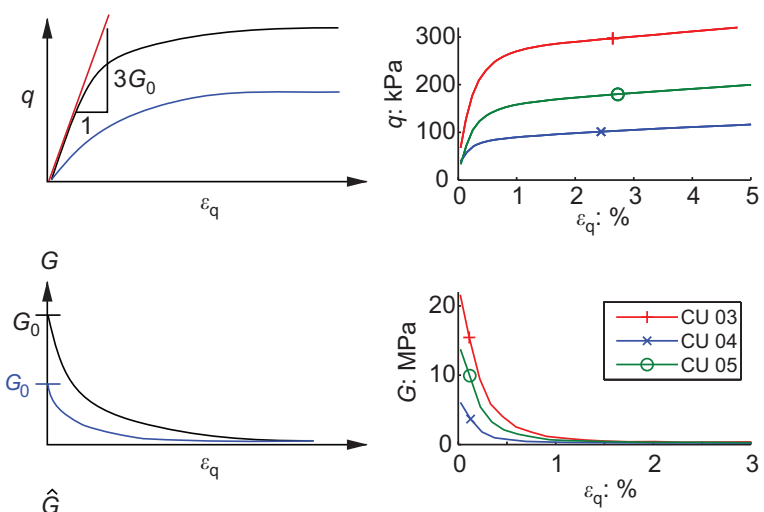

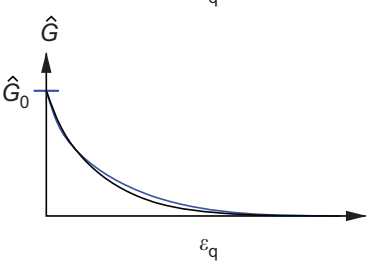

(a)

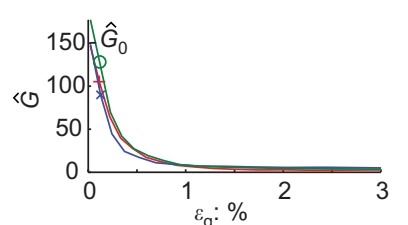

(b)
Fig. 5. Calibration of $\hat{G}_{0}:=G_{0} /\left(p_{0} \cdot e_{\mathrm{c}}\left(p_{0}\right)\right)$ with $G_{0}=\left.G\right|_{\varepsilon_{q}=0}$ on the basis of $\mathrm{CU}$ tests. The experimental results (CU 03, $\mathrm{CU}$ 04 and CU 05) were obtained with Dresden clay 

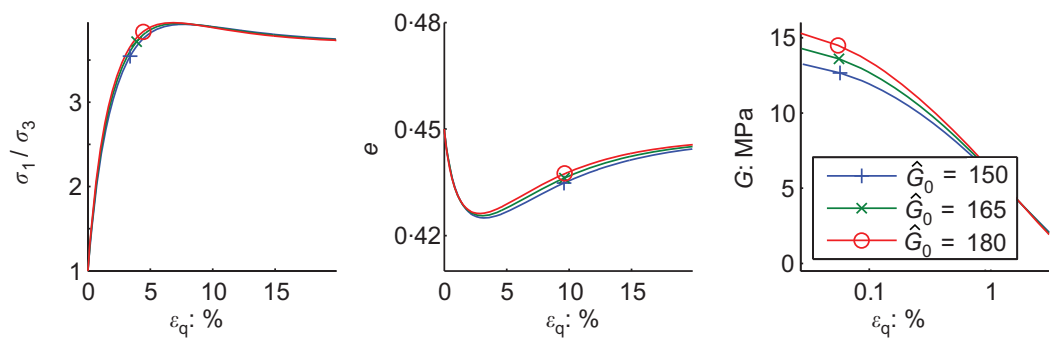

Fig. 6. Influence of the initial normalised stiffness $\hat{G}_{0}$ on numerical simulations of CD tests $\left(\sigma_{3}=200 \mathrm{kPa}\right)$ with barodesy (other material parameters as in Table 1)

$\dot{\mathbf{T}}$ vanishes in equation (2) if $\mathbf{R}^{0}=\mathbf{T}^{0}$ and $f+g=0$. Therefore we set

$$
\frac{R_{2}}{R_{1}}=\frac{\sigma_{2}}{\sigma_{1}}
$$

The stretching at the peak

$$
\mathbf{D}=\left(\begin{array}{ccc}
D_{1} & 0 & 0 \\
0 & D_{2} & 0 \\
0 & 0 & D_{2}
\end{array}\right)
$$

can be evaluated as follows (see Fig. 7(a))

$$
\begin{aligned}
\tan \beta & =\frac{-\dot{\varepsilon}_{\mathrm{V}}}{\dot{\varepsilon}_{1}}=\frac{-\operatorname{tr} \mathbf{D}}{D_{1}}=-\frac{D_{1}+2 D_{2}}{D_{1}} \\
& =-1-\frac{2 D_{2}}{D_{1}} \leadsto D_{2}=\frac{-D_{1}(\tan \beta+1)}{2}
\end{aligned}
$$

From the ratio $D_{2} / D_{1}$, the dilatancy measure $\epsilon=\operatorname{tr} \mathbf{D}^{0}$ can be determined. With $\sigma_{2} / \sigma_{1}=K_{\mathrm{a}}$, we obtain

$$
\frac{R_{2}}{R_{1}}=\frac{\epsilon+c_{1} \exp \left(c_{2} D_{2}^{0}\right)}{\epsilon+c_{1} \exp \left(c_{2} D_{1}^{0}\right)}=K_{\mathrm{a}}
$$

and then

$$
c_{1}=\frac{\epsilon\left(1-K_{\mathrm{a}}\right)}{K_{\mathrm{a}} \exp \left(c_{2} D_{1}^{0}\right)-\exp \left(c_{2} D_{2}^{0}\right)}
$$

With an empirical relationship between certain stress ratios and dilatancy $\tan \beta=-\dot{\varepsilon}_{\mathrm{v}} / \dot{\varepsilon}_{1}$, according to Chu \& Lo (1994) and Luo et al. (2012), determination of $c_{1}$ (equation (16)) can be simplified. Let us consider states characterised with $\mathbf{R}^{0}=\mathbf{T}^{0}$. Such states are (i) proportional paths (e.g. isotropic compression, critical states) and (ii) peak states. Chu \& Lo (1994) observed that the corresponding stress ratios $\eta_{\mathrm{a}}=q / p$ of such states are related to the dilatancy $\tan \beta$ as shown in Fig. 7. For isotropic compression we have $\tan \beta$ $=-3$ and $\eta_{\mathrm{a}}=0$; for undrained triaxial compression $\tan \beta=0$ and, at critical states, $\eta_{\mathrm{a}}=q_{\mathrm{c}} / p_{\mathrm{c}}=6 \sin \varphi_{\mathrm{c}} /\left(3-\sin \varphi_{\mathrm{c}}\right)$. Connecting the states of isotropic compression and the critical state in the $\eta_{\mathrm{a}}-\tan \beta$ plot leads to the following linear relation between $\eta_{\mathrm{a}}$ and $\tan \beta$

$$
\eta_{\mathrm{a}}=\frac{q}{p}=\frac{M}{3} \tan \beta+M \text { with } M=\frac{6 \sin \varphi_{\mathrm{c}}}{3-\sin \varphi_{\mathrm{c}}}
$$

It can be seen from Fig. 7(b) that peak states from drained triaxial (CD) tests can be approximated by equation (17) (i.e. by means of critical friction angle and dilatancy).

We replace $K_{\mathrm{a}}$ with $\left(3-\eta_{\mathrm{a}}\right) /\left(3+2 \eta_{\mathrm{a}}\right)$ in equation (16) and use $\eta_{\mathrm{a}}$ from equation (17) with $\tan \beta=1$ (i.e. $D_{22}=D_{33}=1$ for $D_{11}=-1$ ) to rewrite equation (16) as a function of $\varphi_{\mathrm{c}}$

$$
c_{1}=\frac{-8 \times 3^{1 / 2} \sin \varphi_{\mathrm{c}}}{\left(13 \sin \varphi_{\mathrm{c}}+9\right) K_{\mathrm{c}}^{\sqrt{2} / 3}+\left(11 \sin \varphi_{\mathrm{c}}-9\right)\left(1 / K_{\mathrm{c}}\right)^{\sqrt{2} / 3}}
$$

\section{Calibration of $c_{4}$ and $c_{5}$}

Equation (5) is used for the calibration of $c_{4}$ and $c_{5}$ to achieve that, at isotropic normal compression, barodesy complies with the NCL (see similar approaches by Mašín $(2005,2012))$. Derivation of equation (5) with respect to time $t$ gives

$$
\frac{\dot{e}}{1+e}=-\lambda \frac{\dot{p}}{p}
$$

With $\dot{e} /(1+e)=\operatorname{tr} \mathbf{D}=-3^{1 / 2}|\mathbf{D}|=-3^{1 / 2} \dot{\varepsilon}$ (the equation $\dot{e} /$ $(1+e)=\operatorname{tr} \mathbf{D}$ holds for incompressible grains) and $\sigma=3^{1 / 2} p$, the NCL reads

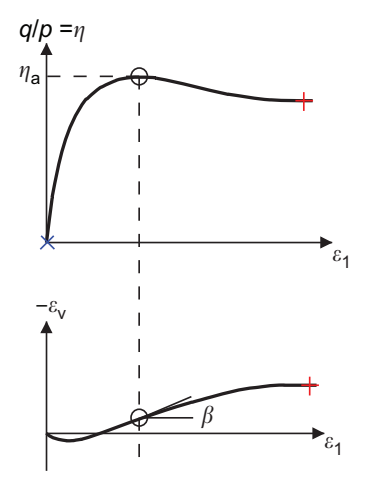

(a)

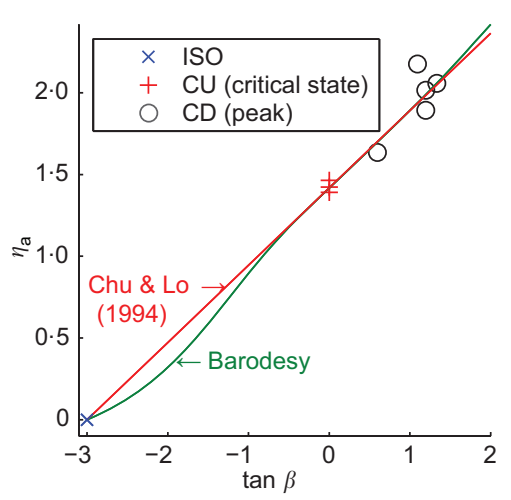

(b)

Fig. 7. Determination of $c_{1}$ based on peak states of $C D$ tests. The experimental results (CU and CD triaxial tests) refer to Dresden clay. (a) CD test: schematic diagram. (b) Stress ratio $\eta_{a}=p / q$ versus dilatancy, according to Chu \& Lo (1994) and Luo et al. (2012) 
Table 1. CSSM parameters used for calibration of barodesy

\begin{tabular}{l|c|c|c|c}
\hline Material & $\begin{array}{c}\varphi_{\mathrm{c}}: \\
\text { degrees }\end{array}$ & $N$ & $\lambda$ & $\hat{G}_{0}$ \\
\hline London clay & $22 \cdot 6$ & $1 \cdot 375$ & $0 \cdot 110$ & 58 \\
Dresden clay & $35 \cdot 0$ & $0 \cdot 622$ & $0 \cdot 038$ & 150 \\
\hline
\end{tabular}

Table 2. Barodesy for clay. Full set of constitutive equations with the abbreviations $\mathbf{X}^{0}=\mathbf{X} /|\mathbf{X}|, \sigma=|\mathbf{T}|, p=-\operatorname{tr} \mathbf{T} / 3, \dot{\varepsilon}=|\mathbf{D}|, \epsilon$ $=\operatorname{tr} \mathbf{D}^{0}$

\begin{tabular}{l|l}
\hline Direction of proportional paths & $\mathbf{R}(\mathbf{D})=\epsilon \mathbf{1}+c_{1} \exp \left(c_{2} \mathbf{D}^{0}\right)$ \\
Constitutive equation & $\mathbf{T}=c_{3} \sigma^{c_{4}} \cdot\left(f \mathbf{R}^{0}+g \mathbf{T}^{0}\right) \cdot \dot{\varepsilon}$ \\
& $f=c_{5} \epsilon-\ln \left(1+e_{\mathrm{c}}\right)$ \\
& $g=\ln (1+e)$ \\
Critical void ratio & $e_{\mathrm{c}}=\exp [N-\lambda \ln (2 p)]-1$ \\
\hline
\end{tabular}

$$
\dot{p}=\sigma \frac{1}{\lambda} \dot{\varepsilon}
$$

With the general form of the barodetic constitutive relation (equation (2)), isotropic compression (i.e. $\mathbf{T}=-p \mathbf{1}, \mathbf{R}^{0}=$ $\left.\mathbf{T}^{0}=-\left(1 / 3^{1 / 2}\right) \mathbf{1}\right)$ yields

$$
\dot{p}=c_{3} \sigma^{c_{4}} \frac{f+g}{3^{1 / 2}} \dot{\varepsilon}
$$

Comparing equations (20) and (21) yields

$$
c_{4}=1
$$

and

$$
\frac{c_{3}}{3^{1 / 2}}(f+g)=\frac{1}{\lambda}
$$

Now we write equation (8) for hydrostatic compression $\left(\epsilon=-3^{1 / 2}\right)$, use equation (23) and obtain

$$
c_{3}\left(\ln (1+e)-N+\lambda \ln \frac{2 p}{p_{\mathrm{r}}}-c_{5} 3^{1 / 2}\right)=\frac{3^{1 / 2}}{\lambda}
$$

Introducing equation (5) into equation (24) leads to

$$
c_{5}=\frac{c_{3} \lambda^{2} \ln 2-3^{1 / 2}}{c_{3} \lambda 3^{1 / 2}}
$$

Equation (25) ensures that a simulation of hydrostatic normal compression with barodesy starting from $e=$ $\exp N-1$ leads to the NCL (see Fig. 2(b)). Note that $c_{4}=1$ for clay, whereas for sand $c_{4}<1$ (Kolymbas, 2011).
Calibration of $c_{3}$

For an undrained test, $\operatorname{tr} \mathbf{D}=0$ (i.e. $\varepsilon_{\mathrm{v}}=\varepsilon_{1}+2 \varepsilon_{2}=0$ ) and therefore $\varepsilon_{q}=(2 / 3)\left(\varepsilon_{1}-\varepsilon_{2}\right)=\varepsilon_{1}$. Hence, equation (13), for isochoric deformation, reads

$$
G=\frac{1}{3} \frac{\partial q}{\partial \varepsilon_{1}}=\frac{1}{3} \frac{\dot{T}_{1}-\dot{T}_{2}}{D_{1}}
$$

From equations (1), (2) and (22) it follows that

$$
G=\frac{\dot{T}_{1}-\dot{T}_{2}}{3 D_{1}}=\frac{c_{3} \sigma \dot{\varepsilon}\left(f R_{1}^{0}+g T_{1}^{0}-f R_{2}^{0}-g T_{2}^{0}\right)}{3 D_{1}}
$$

The shearing in a CU test starts from a hydrostatic stress state $\mathbf{T}=p_{0} \mathbf{1}$ (i.e. $p_{0}=T_{1}=T_{2}=T_{3}$ ). Introducing $f$ from equation (10), $\mathbf{R}$ from equation (1), $\operatorname{tr} \mathbf{D}=0$, $\mathbf{D}=\left(\begin{array}{ccc}-1 & 0 & 0 \\ 0 & 0 \cdot 5 & 0 \\ 0 & 0 & 0 \cdot 5\end{array}\right) \cdot D_{1}$ and $G_{0}=\left.G\right|_{\varepsilon_{q}=0}$ into equation (27) yields

$$
c_{3}=-\frac{G_{0}\left(3 \sin ^{2} \varphi_{\mathrm{c}}-2 \sin \varphi_{\mathrm{c}}+3\right)^{1 / 2}}{2^{1 / 2} \sin \varphi_{\mathrm{c}}\left[N-\lambda \ln \left(2 p_{0}\right)\right] p_{0}}
$$

and, with equation (14), this yields

$$
c_{3}=-\frac{\hat{G}_{0}\left(3 \sin ^{2} \varphi_{\mathrm{c}}-2 \sin \varphi_{\mathrm{c}}+3\right)^{1 / 2}}{2^{1 / 2} \sin \varphi_{\mathrm{c}}}
$$

Note that all parameters $N, \lambda, \varphi_{\mathrm{c}}$ and $\hat{G}_{0}$ can be obtained from one CU triaxial test. Table 1 summarises the material parameters for the considered clays. Table 2 sums up all the equations of barodesy for clay. Determination of the constants $c_{1}-c_{5}$ is summarised in Table 3.

\section{PROPERTIES OF THE MODEL}

To give an idea of the properties of the model, fundamental features are shown. The asymptotic behaviour to critical states is shown in Fig. 8. London clay is simulated with barodesy (Fig. 8) and with Mašín's hypoplastic constitutive model (Mašín, 2005) (Fig. 9). Simulated paths of drained triaxial tests are shown as $p-e$ and $p-q$ plots as well as plots in the normalised stress plane (i.e. $p / p_{\mathrm{e}}-q / p_{\mathrm{e}}$ ), where $p_{\mathrm{e}}$ is Hvorslev's equivalent consolidation pressure on the NCL, given by

$$
p_{\mathrm{e}}=\exp \left(\frac{N-\ln (1+e)}{\lambda}\right)
$$

Table 3. Constants $c_{1}-c_{5}$

$$
\begin{aligned}
& c_{1}=\frac{-8 \times 3^{1 / 2} \sin \varphi_{\mathrm{c}}}{\left(13 \sin \varphi_{\mathrm{c}}+9\right)\left[\left(1-\sin \varphi_{\mathrm{c}}\right) /\left(1+\sin \varphi_{\mathrm{c}}\right)\right]^{\sqrt{2} / 3}+\left(11 \sin \varphi_{\mathrm{c}}-9\right)\left[\left(1+\sin \varphi_{\mathrm{c}}\right) /\left(1-\sin \varphi_{\mathrm{c}}\right)\right]^{\sqrt{2} / 3}} \\
& c_{2}=\left(\frac{2}{3}\right)^{1 / 2} \ln \frac{1-\sin \varphi_{\mathrm{c}}}{1+\sin \varphi_{\mathrm{c}}} \\
& c_{3}=-\frac{\hat{G}_{0}\left(3 \sin ^{2} \varphi_{\mathrm{c}}-2 \sin \varphi_{\mathrm{c}}+3\right)^{1 / 2}}{2^{1 / 2} \sin \varphi_{\mathrm{c}}} \\
& c_{4}=1 \\
& c_{5}=\frac{c_{3} \lambda^{2} \ln 2-3^{1 / 2}}{c_{3} \lambda 3^{1 / 2}}
\end{aligned}
$$



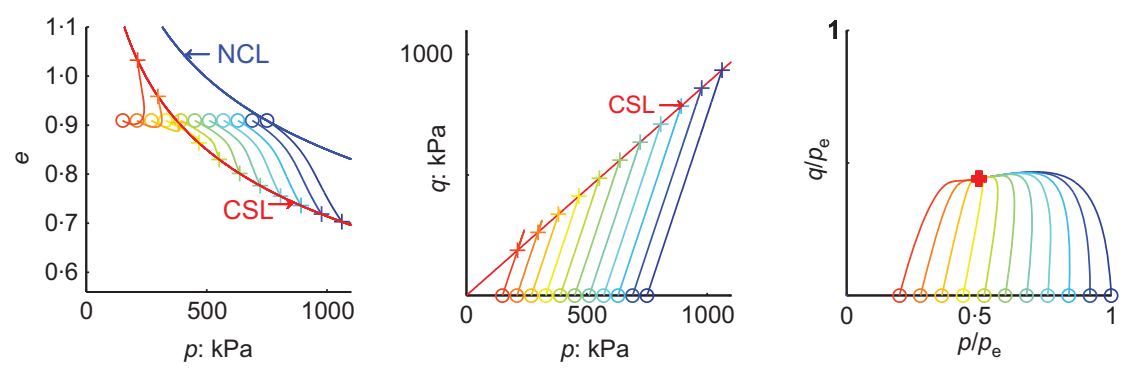

Fig. 8. Barodesy: simulated paths of drained triaxial tests for London clay. The start points are denoted by a circle (o) and the endpoints by a cross $(+)$
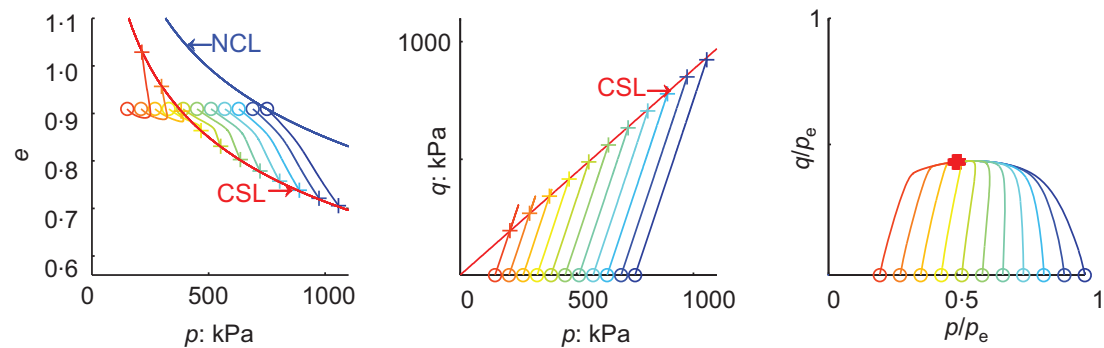

Fig. 9. Hypoplasticity version of Mašín: simulated paths of drained triaxial tests for London clay. The start points are denoted by a circle (o) and the end-points by a cross (+)

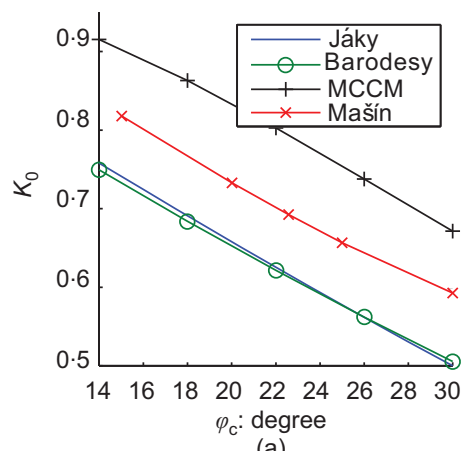

(a)

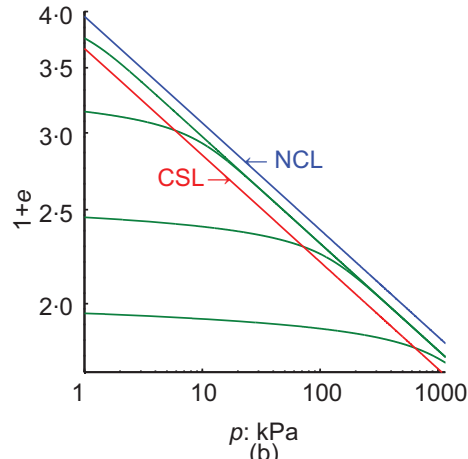

(b)

Fig. 10. Oedometric compression. (a) Jáky's equation $\left(K_{0}=1-\sin \varphi_{c}\right)$ compared with predictions from barodesy, the MCCM and the hypoplastic version of Mašín; MCCM and Mašín data digitalised from Mašín \& Herle (2005). (b) Simulations with barodesy starting from various initial densities

Figure 10(a) shows $K_{0}$ predictions of different models compared with Jáky's equation $\left(K_{0}=1-\sin \varphi_{\mathrm{c}}\right)$. As reported by Mašín \& Herle (2005), based on experimental data (Mayne \& Kulhawy, 1982), Jáky's prediction for $K_{0}$ is suitable for clay. The $K_{0}$ predictions of the MCCM and the hypoplastic version of Mašín were taken from Mašín \& Herle (2005).

Figure 10(b) shows the asymptotic behaviour under oedometric compression. The uniaxial compression tests start from various initial densities. Further information of the performance of the model is given in the next section.

Table 4. CSSM parameters used for calibration of Mašín (2005)

\begin{tabular}{l|c|c|c|c|c}
\hline Material & $\varphi_{\mathrm{c}}$ : degrees & $N$ & $\lambda$ & $\kappa$ & $r$ \\
\hline London clay & $22 \cdot 6$ & $1 \cdot 375$ & $0 \cdot 11$ & $0 \cdot 016$ & $0 \cdot 4$ \\
\hline
\end{tabular}

\section{SIMULATION OF ELEMENT TESTS}

Numerical simulations are compared with experiments and with Mašín's hypoplastic constitutive model for clay (Mašín, 2005), see Table 4 and with the MCCM (Roscoe \& Burland, 1968), see Table 5. The MCCM was applied according to Butterfield (1979) (i.e. the NCL is assumed as linear in a log-log plot). The parameters $N, \lambda, \kappa$ and $\varphi_{\mathrm{c}}$ of the MCCM correspond to the parameters of the hypoplastic constitutive model for clay of Mašín (2005) and the initial shear stiffness $G_{0}$ is chosen according to Mašín (2004). Note that in Tables 4 and 5, the parameters $\lambda$ and $\kappa$ correspond to those denoted by Mašín (2005) as $\lambda^{*}$ and $\kappa^{*}$.

Table 5. CSSM parameters used for calibration of the MCCM, according to Butterfield (1979)

\begin{tabular}{l|c|c|c|c|c}
\hline Material & $\varphi_{\mathrm{c}}:$ degrees & $N$ & $\lambda$ & $\kappa$ & $G_{0}: \mathrm{MPa}$ \\
\hline London clay & $22 \cdot 6$ & $1 \cdot 375$ & $0 \cdot 11$ & $0 \cdot 016$ & 5 \\
\hline
\end{tabular}


Table 6. Clay characteristics

\begin{tabular}{l|c|c|c|c|c}
\hline Material & Major clay mineral type & Proportion of clay: \% & $w_{\mathrm{p}}: \%$ & $w_{1}: \%$ & $I_{\mathrm{p}}: \%$ \\
\hline Dresden clay & Muscovite/illite & 21 & 19 & 34 & $16 \cdot 5$ \\
London clay (Mašín, 2004) & Illite & 53 & $20-30$ & $60-80$ & $40 \cdot 0$ \\
\hline
\end{tabular}

Table 7. Simulations of element tests and experimental results shown in this article

\begin{tabular}{l|l|l|l}
\hline Test & & Material & \\
\hline Isotropic compression & Fig. 2(b) & $\begin{array}{l}\text { Dresden clay } \\
\text { Dresden clay }\end{array}$ & Barodesy \\
Triaxial CD & Fig. 6 & Dresden clay & Barodesy \\
Triaxial CD, CU & Fig. 7(b) & London clay & Barodesy \\
Triaxial CD & Fig. 8 & London clay & Mašín (2005) \\
Triaxial CD & Fig. 9 & London clay & Barodesy \\
Oedometric compression & Fig. 10(b) & London clay & Barodesy (Mašín, 2005) \\
Triaxial CD & Fig. 11(a) & MCCM (Roscoe \& Burland, 1968) \\
$p=$ constant & Fig. 11(b) & & Barodesy (Mašín, 2005) \\
Isotropic compression & & & MCCM (Roscoe \& Burland, 1968) \\
\end{tabular}

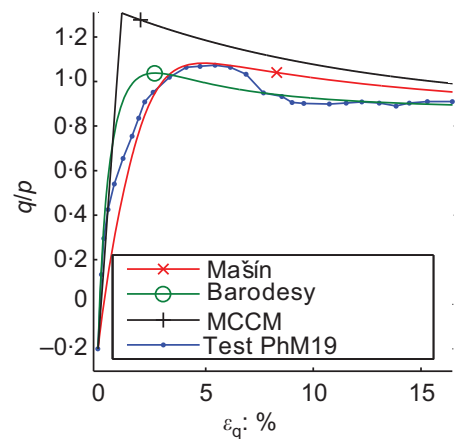

(a)

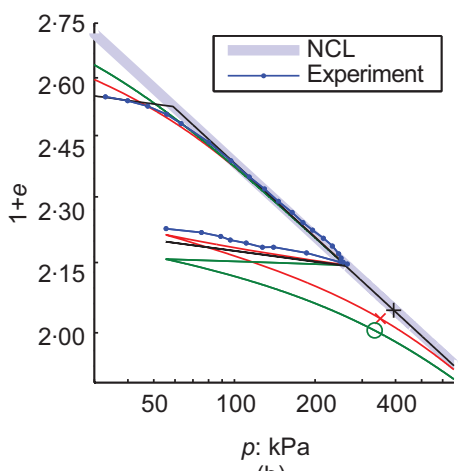

(b)

Fig. 11. Numerical simulations obtained with barodesy, hypoplastic model of Mašín (2005) and the MCCM; London clay data digitalised from Mašín (2005). (a) Triaxial compression tests $\left(p=110 \mathrm{kPa}=\right.$ constant, $\left.e_{\mathrm{ini}}=1 \cdot 115\right)$. (b) Isotropic compression tests

Basic characteristics such as the liquid limit $w_{1}$, the plastic limit $w_{\mathrm{p}}$ and the plasticity index $I_{\mathrm{p}}$ of the simulated clays are shown in Table 6.

Table 7 gives an overview of the numerical simulations presented in this article. Figure 11(a) shows simulations of triaxial tests with constant mean pressure starting from $K_{0}$ consolidated states. In Figs 2(b) and 11(b), simulations of isotropic compression tests are compared with experimental data. Note that the parameter $\kappa$, which governs the unloading stiffness, is used in the Mašin model and the MCCM. No corresponding parameter is used in barodesy: consequently, the unloading stiffness under isotropic compression is overestimated with barodesy (see Fig. 11(b)). Note that constitutive relations of the type $\dot{\mathbf{T}}=\mathbf{h}(\mathbf{T}, \mathbf{D}, e)$ have a simple structure and cannot capture reloading.

\section{CONCLUSIONS}

This article has shown that barodesy is able to describe important characteristics of clay behaviour for monotonic loading. Cyclic behaviour is not captured by the model presented here; this modelling is left for future publications. The constitutive equations are simple: they consist of one differential equation and one tensorial function with five constants that can be determined from well-known material parameters of soil mechanics. It was shown that barodesy comprises concepts of CSSM. Despite its mathematical simplicity, the numerical simulations are satisfactory. The constitutive equations are easy to understand and this offers potential for further development.

\section{Acknowledgement}

The laboratory test results of Dresden clay in Figs 2(b), 4, 5 and 7 (b) were kindly provided by Prof. I. Herle (TU Dresden).

\section{REFERENCES}

Bergholz, K. (2009). Experimentelle Bestimmung von nichtlinearen Spannungsgrenzbeziehungen. Masters thesis, Technische Universität Dresden, Dresden.

Butterfield, R. (1979). A natural compression law for soils (an advance on e-log p'). Géotechnique 290, No. 4, 469-480.

Chu, J. \& and Lo, S.-C. R. (1994). Asymptotic behaviour of a granular soil in strain path testing. Géotechnique 44, No. 1, 65-82.

Fellin, W. \& Ostermann, A. (2011). The critical state behaviour of barodesy compared with the Matsuoka-Nakai failure criterion. Int. J. Num. Anal. Methods Geomech. http://dx.doi.org/10. 1002/nag. 1111 .

Goldscheider, M. (1976). Grenzbedingung und Fließregel von Sand. Mech. Res. Commun. 3, No. 6, 463-468.

Kolymbas, D. (1977). A rate-dependent constitutive equation for soils. Mech. Res. Commun 4, No. 6, 367-372.

Kolymbas, D. (1985). A generalized hypoelastic constitutive law. Proc. 11th Int. Conf. Soil Mech. Found. Engng, San Francisco 5, 2626.

Kolymbas, D. (1991). An outline of hypoplasticity. Arch. Appl. Mech. 61, No. 3, 143-151, http://dx.doi.org/10.1007/BF00788048. 
Kolymbas, D. (2000). Advances in geotechnical engineering and tunnelling. I Introduction to hypoplasticity. Rotterdam: Balkema.

Kolymbas, D. (2009). Sand as an archetypical natural solid. In Mechanics of natural solids (Kolymbas, D. \& Viggiani, G. (eds)). Berlin: Springer, pp. 1-26.

Kolymbas, D. (2011). Barodesy: a new hypoplastic approach. Int. J. Num. Anal. Methods Geomech. http://dx.doi.org/10.1002/ nag. 1051.

Kolymbas, D. (2012). Barodesy: a new constitutive frame for soils. Géotech. Lett. 2, 17-23, http://dx.doi.org/10.1680/geolett.12.00004

Luo, T., Yao, Y.-P., Zhou, A.-N. \& Tian, X.-G. (2012). A three-dimensional criterion for asymptotic states. Comput. Geotech. 410, 90-94, http://dx.doi.org/10.1016/j.compgeo.2011. 12.002 .
Mašín, D. (2004). Laboratory and numerical modelling of natural clay. MPhil thesis, City University, London.

Mašín, D. (2005) A hypoplastic constitutive model for clays. Int. J. Num. Anal. Methods Geomech. 29, No. 4, 311-336.

Mašín, D. (2012). Hypoplastic cam-clay model. Géotechnique 620, No. 6, 549-553.

Mašín, D. \& Herle, I. (2005). State boundary surface of a hypoplastic model for clays. Comput. Geotech. 320, No. 6, 400410, http://dx.doi.org/10.1016/j.compgeo.2005.09.001.

Mayne, P. \& Kulhawy, F. (1982). K0-ocr relationships in soil. $J$. Geotech. Engng 108, No. 6, 851-872.

Roscoe, K. \& Burland, J. (1968). On the generalised stress-strain behaviour of wet clay. In Engineering plasticity (Heyman, J.J. \& Leckie, F. (eds)). Cambridge: Cambridge University Press, pp. 535-609.

\section{WHAT DO YOU THINK?}

To discuss this paper, please email up to 500 words to the editor at journals@ice.org.uk. Your contribution will be forwarded to the author(s) for a reply and, if considered appropriate by the editorial panel, will be published as a discussion. 